\title{
Preparation and optical properties of novel bioactive photonic crystals obtained from core-shell poly (styrene/ $\alpha$-tert-butoxy- $\omega$-vinylbenzyl-polyglycidol) microspheres
}

\author{
Monika Gosecka • Nebewia Griffete • \\ Claire Mangeney • Mohamed M. Chehimi •
}

Stanislaw Slomkowski • Teresa Basinska

Received: 20 October 2010 /Revised: 6 May 2011 /Accepted: 11 May 2011 /Published online: 29 June 2011

(C) The Author(s) 2011. This article is published with open access at Springerlink.com

\begin{abstract}
Optical properties of polymer microspheres with polystyrene cores and polyglycidol-enriched shells poly (styrene/ $\alpha$-tert-butoxy- $\omega$-vinylbenzyl-polyglycidol) $(\mathrm{P}(\mathrm{S} /$ PGL) particles with number average diameters $D_{n}$ determined by scanning electron microscopy equal 237 and $271 \mathrm{~nm}$ ), were studied before and after immobilization of ovalbumin. The particles were synthesized by emulsifier-free emulsion copolymerization of styrene and polyglycidol macromonomer (poly(styrene/ $\alpha$-tert-butoxy- $\omega$-vinylbenzylpolyglycidol)) initiated with potassium persulfate. Molar fraction of polyglycidol units in the interfacial layer of the microspheres determined by XPS was equal 42.6 and $34.0 \%$, for the particles with $D_{n}$ equal 137 and $271 \mathrm{~nm}$, respectively. Colloidal crystals from the aforementioned particles were prepared by deposition of particle suspensions on the glass slides and subsequent evaporation of water. It was found that optical properties of colloidal crystals from the $\mathrm{P}(\mathrm{S} / \mathrm{PGL})$ microspheres strongly depend on modification of their interfacial layer by covalent immobilization of ovalbumin. The coating of particles with ovalbumin resulted in decreasing their refractive index from 1.58 to 1.52 .
\end{abstract}

M. Gosecka $\cdot$ S. Slomkowski $\cdot$ T. Basinska $(\bowtie)$

Center of Molecular and Macromolecular Studies,

Polish Academy of Sciences,

Sienkiewicza 112,

90-363 Lodz, Poland

e-mail: basinska@cbmm.lodz.pl

N. Griffete $\cdot$ C. Mangeney $(\bowtie) \cdot$ M. M. Chehimi

Interfaces, Traitements,

Organisation et Dynamique des Systèmes (ITODYS),

Université Paris Diderot-CNRS (UMR 7086),

15 rue Jean de Baif,

75013 Paris, France

e-mail: mangeney@univ-paris-diderot.fr
Keywords Hydrophilic microspheres · Core-shell particles $\cdot$ Polyglycidol $\cdot$ Colloidal photonic crystals . Optical properties

\section{Introduction}

The term colloidal crystals denote periodic arrays composed from highly uniform particles (usually with diameters in the range from 100 to $400 \mathrm{~nm}$ ). Especially interesting are colloidal crystals made from dielectric materials, in particular from polymers or silica. Optical properties of these crystals (often called photonic crystals) strongly depend on refractive indices of constituting particles and on the interparticular distance what makes these materials useful for preparation of various kind of sensors with optical detection.

In majority of studies, researchers investigated properties of colloidal crystals made from the hard inorganic particles like silica [1], metals (for example gold [2, 3]), metal oxides like $\mathrm{In}_{2} \mathrm{O}_{3}$ [4], $\mathrm{TiO}_{2}$ [5], and homopolymers like polystyrene [6, 7]. However, for biosensors, there are needed colloidal crystals made from particles suitable for efficient binding of biomolecules. Particles with the aforementioned properties often have a core-shell morphology and are composed from solid hydrophobic cores providing necessary mechanical properties and soft, hydrophilic, gel-like shells which swell in water and contain chemical groups suitable for covalent immobilization of biomacromolecules. It is worth noting that studies on preparation and properties of photonic crystals from uniform polymer core-shell particles, whose cores and shells are composed from polymers which differ in hydrophilicity are very limited. For example, Okamoto et al. 
characterized colloidal crystals prepared from particles containing polystyrene core and poly(ethylene oxide) shell [8]. However, studies on optical properties of colloidal crystals modified by binding proteins or other biologically active molecules were very scarcely investigated.

Some time ago, we developed method for synthesis of core-shell microspheres with hydrophobic polystyrene cores and shells enriched with poly(styrene/ $\alpha$-tert-butoxy$\omega$-vinylbenzyl-polyglycidol) (P(S/PGL) microspheres, see Scheme 1) by emulsifier-free emulsion copolymerization of styrene and $\alpha$-tert-butoxy- $\omega$-vinylbenzyl-polyglycidol [9].

It is worth noting that main chain of polyglycidol and poly(ethylene oxide) known as steric stabilizer of colloidal particles and protecting agent reducing protein adsorption [10-13] are very similar. However, in polyglycidol, each repeating unit contains methylhydroxy group which upon appropriate activation could be used for covalent immobilization of proteins and amino terminated oligonucleotides. Thus, the microspheres with polystyrene core and polyglycidol-rich shells are interesting building blocks for preparation and studies of optical properties of colloidal crystals with and without immobilized biomolecules. The aim of this work is to prepare photonic crystals from $\mathrm{P}(\mathrm{S} / \mathrm{PGL})$ microspheres and to compare the Bragg peak values for colloidal crystals prepared from particles with covalently immobilized ovalbumin (used as model globular protein; molecular weight 43,000 ) and without any ovalbumin attached to the particles surface. Results of studies of these photonic crystals could be used as a basis for design of protein sensors.

Colloidal crystals can be prepared by various ways including soft lithography related methods [14], gravity sedimentation [15], self-assembly of particles between parallel plates and subsequent immobilization of the spheres in polymer film prior to solvent evaporation [16], and crystallization of colloidal particles by solvent evaporation in capillaries [17]. Alternatively, in set of papers, Ravaine et al. [18-20] and other research groups [21] described the formation of colloidal crystals via the elegant Langmuir-Blodgett-based procedure. Colloidal crystals can be prepared also by solvent evaporation method. Properties of colloidal crystals formed in this way were smartly tuned by the application of a thermal

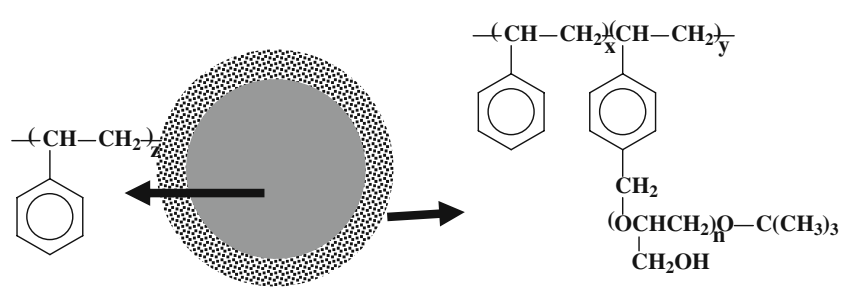

Scheme $1 \mathrm{P}(\mathrm{S} / \mathrm{PGL})$ microspheres with core-shell morphology stress [22] or by the application of external magnetic field $[23,24]$.

In our work, we decided to prepare colloidal crystals from $\mathrm{P}(\mathrm{S} / \mathrm{PGL})$ microspheres on glass slides by a simple solvent evaporation method from precisely determined volume of particle suspension carried on at controlled temperature.

\section{Materials and methods}

Materials

Styrene (Aldrich) was purified from the stabilizer (4tert-butylcatechol) by distillation at $30{ }^{\circ} \mathrm{C}$ carried on at reduced pressure. An $\alpha$-tert-butoxy- $\omega$-vinylbenzyl-polyglycidol macromonomer (shown in Scheme 2) was obtained by anionic polymerization of 1,1-ethyl-ethoxyglycidyl ether initiated with potassium tert-butoxide, termination of propagation active centers with p-chloromethylstyrene and subsequent hydrolysis of ethyl ethoxy groups by oxalic acid. The details of synthesis of PGL macromonomer were described elsewhere [25]. Potassium persulfate $\left(\mathrm{K}_{2} \mathrm{~S}_{2} \mathrm{O}_{8}\right.$, from Fluka) was used without further purification. Water for synthesis of microspheres was distilled three times and its $\mathrm{pH}$ was adjusted to 6.8 with $\mathrm{KHCO}_{3}$.

\section{Preparation of $\mathrm{P}(\mathrm{S} / \mathrm{PGL})$ microspheres}

$\mathrm{P}(\mathrm{S} / \mathrm{PGL})$ were synthesized by emulsion polymerization of styrene and PGL with $M_{n}=2,700$ and $M_{w} / M_{n}=1.05$. The details of synthesis were described in our earlier paper [9].

\section{Characterization of $\mathrm{P}(\mathrm{S} / \mathrm{PGL})$ microspheres}

Diameters of microspheres were determined by analysis of scanning electron microscopy (SEM) microphotographs registered using a JEOL 5500LV apparatus. The specimens were coated with gold prior to analysis. Number average diameter of microspheres $\left(D_{n}\right)$ and diameter polydispersity parameter $\left(D_{w} / D_{n}\right)$ were calculated on a basis of measure-

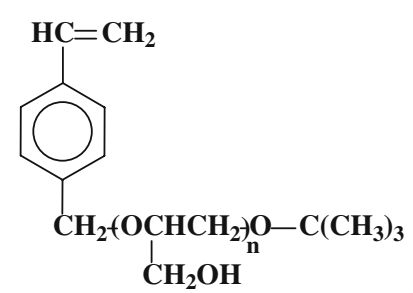

Scheme 2 Structure of $\alpha$-tert-butoxy- $\omega$-vinylbenzyl-polyglycidol macromonomer 
ments of diameters of at least 800 microspheres (randomly chosen in different microphotographs).

Concentration of acidic groups on the surface of microspheres was determined by conductometric titration using potassium hydroxide. Prior to titration, a sample of suspension of microspheres was passed through a Dowex 50WX4 ion-exchange resin with purpose to replace potassium cations by protons.

\section{X-ray photoelectron spectroscopy measurements}

Chemical composition of interfacial layer of $\mathrm{P}(\mathrm{S} / \mathrm{PGL})$ microspheres was determined by X-ray photoelectron spectroscopy [26]. Spectra were recorded using a Thermo VG Scientific ESCALAB 250 system equipped with a monochromatic Al K $\alpha$ X-ray source $(1,486.6 \mathrm{eV})$ and a magnetic lens which increases sensitivity. An X-ray beam of $650 \mu \mathrm{m}$ diameter was used at $20 \mathrm{~mA}$ and $15 \mathrm{kV}$. The spectra were acquired in the constant analyzer energy mode with pass energy of 150 and $40 \mathrm{eV}$ for the survey and the narrow regions, respectively. Charge compensation was achieved with an electron flood gun operated in the presence of argon at a partial pressure of $2 \times 10^{-8} \mathrm{mbar}$. Atomic ratio of carbon and oxygen atoms were calculated from the ratio of the intensity of corresponding XPS signals corrected for the relevant sensitivity factors.

\section{Photon correlation spectroscopy measurements}

Hydrodynamic diameter of $\mathrm{P}(\mathrm{S} / \mathrm{PGL})$ microspheres was determined by photon correlation spectroscopy measurements (PCS) using a Zetasizer Nano ZEN3600 (Malvern Instruments). The apparatus was equipped with a $\mathrm{He}-\mathrm{Ne}$ laseremitting light at $633 \mathrm{~nm}$ and a detector recording intensity of light scattered at $90^{\circ}$. The hydrodynamic diameters of $\mathrm{P}(\mathrm{S} /$ PGL) microspheres were measured at $25{ }^{\circ} \mathrm{C}$. Prior to measurements the particles were suspended in distilled water containing $10^{-3} \mathrm{M} \mathrm{NaCl}$ and filtered through a $0.2 \mu \mathrm{m}$ chromatographic filter (Millipore). Determination of diffusion coefficient of spherical particles measured by PCS allows calculation of their effective hydrodynamic diameter $\left(D_{h}\right)$ according to the Einstein-Stokes Eq. 1:

$D=\mathrm{kT} / 3 \pi \eta D_{h}$

where, $D$ denotes diffusion coefficient, $D_{h}$ hydrodynamic diameter of microspheres, $k$ Boltzmann constant, $T$ temperature, and $\eta$ viscosity of medium. Obtained data were analyzed using a cumulants method on the basis of at least 80 measurements for each sample. The cumulants method (according to ISO13321) is recommended for calculation of hydrodynamic diameters of spherical particles with low dispersity.
Determination of electrophoretic mobilities $(\mu)$ of $\mathrm{P}(\mathrm{S} / \mathrm{PGL})$ microspheres

Electrophoretic mobilities $(\mu)$ of $\mathrm{P}(\mathrm{S} / \mathrm{PGL})$ microspheres were measured using a Zetasizer Nano ZEN3600, (Malvern, UK) equipped with a cell with electrodes to which a controlled potential (up to $400 \mathrm{~V}$ ) was applied. The electrophoretic mobility measurements were performed at $25{ }^{\circ} \mathrm{C}$ for $8 \mathrm{ml}$ samples containing suspensions of $\mathrm{P}(\mathrm{S} / \mathrm{PGL})$ microspheres. The mean of 10 measurements registered at required number of counts (usually ca. 2,000 kCps) were taken for analysis.

Immobilization of ovalbumin on the surface of $\mathrm{P}(\mathrm{S} / \mathrm{PGL})$ microspheres

Hydroxyl groups of polyglycidol chains in the interfacial layer of $\mathrm{P}(\mathrm{S} / \mathrm{PGL})$ particles require activation prior to covalent attachment of protein. Thus, the suspension of microspheres (usually ca. $0.3 \mathrm{~g}$ of microspheres in $2.0 \mathrm{ml}$ of water) was incubated with 1,3,5-trichlorotriazine dissolved in $3 \mathrm{ml}$ of dioxane (in a ratio 1:0.45 w/w) which was carried on at room temperature during $3 \mathrm{~h}$. Then, the microspheres with activated surface hydroxyl groups were isolated by three times repeated centrifugation and suspended finally in distilled water. Thereafter, the solution of ovalbumin in phosphate buffered saline (PBS) buffer $(\mathrm{pH}=7.4, I=0.2 \mathrm{M})$ was added to suspension of particles yielding a mixture with concentrations of protein and microspheres equal $5 \times$ $10^{-4}$ and $3 \times 10^{-3} \mathrm{~g} / \mathrm{ml}$, respectively. The mixture was incubated overnight at room temperature with gentle shaking. Then, the particles with immobilized ovalbumin were purified by centrifugation and kept for preparation of photonic assemblies. The first supernatant was stored for determination of protein concentration. The amount of immobilized ovalbumin was evaluated on the basis of the difference of concentration of protein in solution before and after incubation with activated $\mathrm{P}(\mathrm{S} / \mathrm{PGL})$ particles. Concentrations of ovalbumin in solutions were measured using a standard Lowry method [27].

Preparation of colloidal assemblies

Clean glass slides $(10 \times 30 \times 0.5 \mathrm{~mm})$ were first treated with a piranha solution $\left(\mathrm{H}_{2} \mathrm{O}_{2} / \mathrm{H}_{2} \mathrm{SO}_{4} 1: 4 \mathrm{vol} / \mathrm{vol}\right)$ in order to make them hydrophilic. Thereafter, the plates were extensively washed with distilled water and dried at room temperature. The slides, pretreated as it was described above, were used as substrates for preparation of colloidal crystals from $\mathrm{P}(\mathrm{S} / \mathrm{PGL})$ microspheres. For this purpose, $100 \mu 1$ of the suspension of $\mathrm{P}(\mathrm{S} / \mathrm{PGL})$ microspheres $(6 \%$ $\mathrm{wt} / v$ solid content) was gently deposited onto the glass plate and dried at $25{ }^{\circ} \mathrm{C}$ in argon atmosphere. Obtained samples 
Table 1 Characteristics of $\mathrm{P}(\mathrm{S} / \mathrm{PGL})$ microspheres used for preparation of photonic crystals

\begin{tabular}{llllll}
\hline $\mathrm{P}(\mathrm{S} / \mathrm{PGL})$ particles & $\begin{array}{l}\text { Styrene/PGL in monomers } \\
\text { feed }(\mathrm{mol} / \mathrm{mol})\end{array}$ & $\begin{array}{l}\text { Number average } \\
\text { diameters }(\mathrm{nm} ; \mathrm{SEM})\end{array}$ & $\begin{array}{l}\text { Dispersity } \\
\text { parameter }\left(D_{w} / D_{n}\right)\end{array}$ & $\begin{array}{l}\text { Sulfate groups } \\
\text { concentration }\left(\mathrm{mol} \times \mathrm{m}^{-2}\right)\end{array}$ & $\begin{array}{l}\text { Surface fraction of } \\
\text { polyglycidol }^{\mathrm{a}}(\mathrm{mol} \%)\end{array}$ \\
\hline $\mathrm{P}(\mathrm{S} / \mathrm{PGL}) 1$ & $3.47 \times 10^{-3}$ & 237 & 1.004 & $4.13 \times 10^{-7}$ & 42.6 \\
$\mathrm{P}(\mathrm{S} / \mathrm{PGL}) 2$ & $2.60 \times 10^{-3}$ & 271 & 1.010 & $6.61 \times 10^{-7}$ & 34.0 \\
\hline
\end{tabular}

${ }^{\mathrm{a}}$ From XPS measurements

protected from dust and other impurities were kept for further analyses.

Scanning electron microscopy monitoring of colloidal crystals from $\mathrm{P}(\mathrm{S} / \mathrm{PGL})$ particles

SEM micrographs of colloidal crystals formed on glass slides were obtained using a Cambridge 120 apparatus fitted with a zirconated tungsten filament. The acceleration voltage was set at $20 \mathrm{kV}$. In order to minimize static charging effects, all specimens were coated with gold prior to analysis.

Ultraviolet-visible (UV-Vis) studies of photonic crystals prepared from $\mathrm{P}(\mathrm{S} / \mathrm{PGL})$ microspheres

The angle-resolved UV-Vis spectra were recorded using SPECORD S600 Analytik Jena spectrophotometer equipped with a variable angle reflectance attachment, operated in the range $15-60^{\circ}$. The samples were illuminated with a collimated fiber halogen light source covering the whole $350-820 \mathrm{~nm}$ spectral range. The reflected light was collected by a second optical fiber symmetric to the first one.

\section{Results and discussion}

\section{Characterization of $\mathrm{P}(\mathrm{S} / \mathrm{PGL})$ microspheres}

The core-shell P(S/PGL) microspheres were synthesized by emulsifier-free emulsion polymerization of styrene and water soluble PGL macromonomer. Two types of particles were synthesized: $\mathrm{P}(\mathrm{S} / \mathrm{PGL} 1)$ and $\mathrm{P}(\mathrm{S} / \mathrm{PGL} 2)$ with initial proportion of styrene and PGL macromonomer in reaction mixture equal $1: 3.47 \times 10^{-3}$ and $1: 2.60 \times 10^{-3}$, respectively.
In our earlier studies, we found that microspheres of this type have hydrophilic shells enriched with polyglycidol, depending on the fraction of PGL macromonomer in the polymerizing mixture [21].

Table 1 reports the characteristic features of $\mathrm{P}(\mathrm{S} / \mathrm{PGL})$ microspheres. It is worth to stress that diameter dispersity of synthesized particles is very low $\left(D_{w} / D_{n} \leq 1.01\right.$, where $D_{w}$ and $D_{n}$ denote the weight and number average diameters, respectively). It has to be noted also that the particles are negatively charged. Their negative charge is due to the presence of sulfate end-groups formed during initiation with potassium persulfate. The surface fraction of polyglycidol was determined from the known proportions of oxygen and carbon atoms in polyglycidol and polystyrene repeating units and proportion of oxygen and carbon atoms measured by XPS method for P(S/PGL) particles. Results given in Table 1 clearly indicate that interfacial layer of these microspheres is rich in hydrophilic polyglycidol. However, one cannot exclude that polystyrene domains are also present in the interfacial layer. Apparently, the copolymer chains with molar fraction of polyglycidol exceeding ca $45 \%$ are water soluble and remain in water not incorporated into the particles' interfacial layer.

According to data from Table 1, the properties of microspheres synthesized during our studies suggested that that these particles should be suitable for formation of colloidal crystals. They are very uniform (diameter dispersity parameter is close to 1) which allows their dense packing into almost defect-free colloidal crystals. The sulfate groups present in the particles' interfacial layers ensure their electrostatic stabilization. Moreover, the microspheres are additionally sterically stabilized by covalently bound water soluble polyglycidol. We did check that the $\mathrm{P}(\mathrm{S} / \mathrm{PGL} 1)$ and $\mathrm{P}(\mathrm{S} / \mathrm{PGL} 2)$ particles are very stable in a broad range of $\mathrm{pH}$ (from 2.5 to 10.0 ) and are resistant to spontaneous aggregation.
Scheme 3 Preparation method of photonic crystals
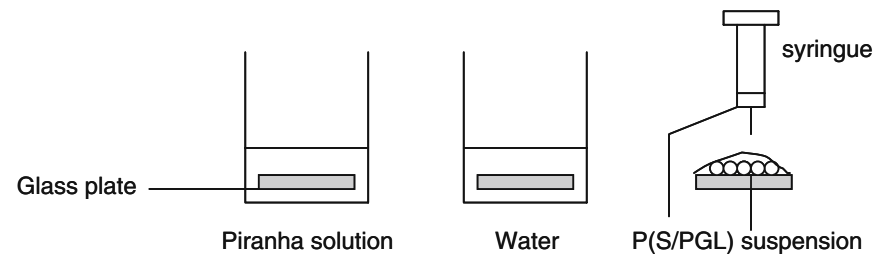

8980808

$\mathrm{P}(\mathrm{S} / \mathrm{PGL})$ crystals 


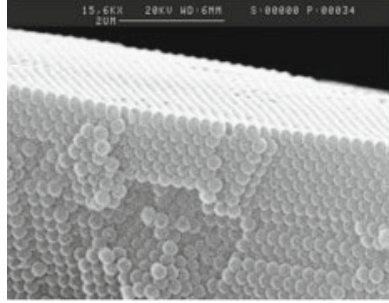

$\mathrm{P}(\mathrm{S} / \mathrm{PGL1})-237 \mathrm{~nm}$

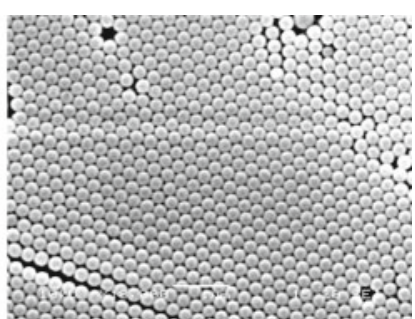

$\mathrm{P}(\mathrm{S} / \mathrm{PGL} 2)-271 \mathrm{~nm}$
Fig. 1 SEM micrographs of 3D assemblies formed from P(S/PGL1) $\left(D_{n}=237 \mathrm{~nm}\right)$ and $\mathrm{P}(\mathrm{S} / \mathrm{PGL} 2)\left(D_{n}=271 \mathrm{~nm}\right)$

Formation and optical properties of 3D colloidal arrays from $\mathrm{P}(\mathrm{S} / \mathrm{PGL})$ microspheres

The protocol for preparing photonic crystals from PGL particles without and with attached ovalbumin was the same. It was described in experimental part and is schematically illustrated in Scheme 3.

We noticed that the colloidal crystal from $\mathrm{P}(\mathrm{S} / \mathrm{PGL} 1)$ and $\mathrm{P}(\mathrm{S} / \mathrm{PGL} 2)$ prepared on the glass slides are very stable upon drying. Probably the flexible polyglycidol containing shells facilitate formation of the close-packed ordered and stable structures due migration of polyglycidol segments across boundaries separating individual particles during the drying process.

Figure 1 shows the typical SEM images of colloidal crystals from $\mathrm{P}(\mathrm{S} / \mathrm{PGL} 1)\left(D_{n}=237 \mathrm{~nm}\right)$ and $\mathrm{P}(\mathrm{S} / \mathrm{PGL} 1)$ $\left(D_{n}=271 \mathrm{~nm}\right)$.

It is worth noting that these crystals contain a low number of defects. The photonic crystal synthesized is very well organized.

Photographs of $\mathrm{P}(\mathrm{S} / \mathrm{PGL})$ particle assemblies recorded in transmitted and reflected (at $90^{\circ}$ ) are shown in Fig. 2.

Photographs in Fig. 2 reveal that a small difference in particles diameters (equal $34 \mathrm{~nm}$ ) accounts for completely different reflection colors. Thus, angle-resolved spectroscopy was employed to determine the wavelength of the Bragg diffraction peak maxima determined for the colloidal crystals prepared from $\mathrm{P}(\mathrm{S} / \mathrm{PGL} 1)$ and $\mathrm{P}(\mathrm{S} / \mathrm{PGL} 2)$ particles. Figure $3 \mathrm{a}$ shows the Bragg diffraction spectra registered for selected incidence light angles $(\theta$, angle between the incidence light and normal to the surface) for particles with

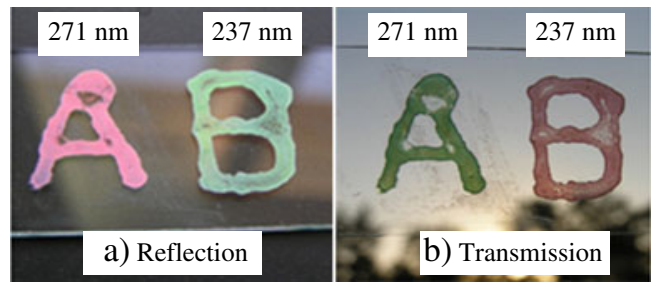

Fig. 2 Reflection (a) and transmission (b) photographs of crystals prepared from particles with various diameters
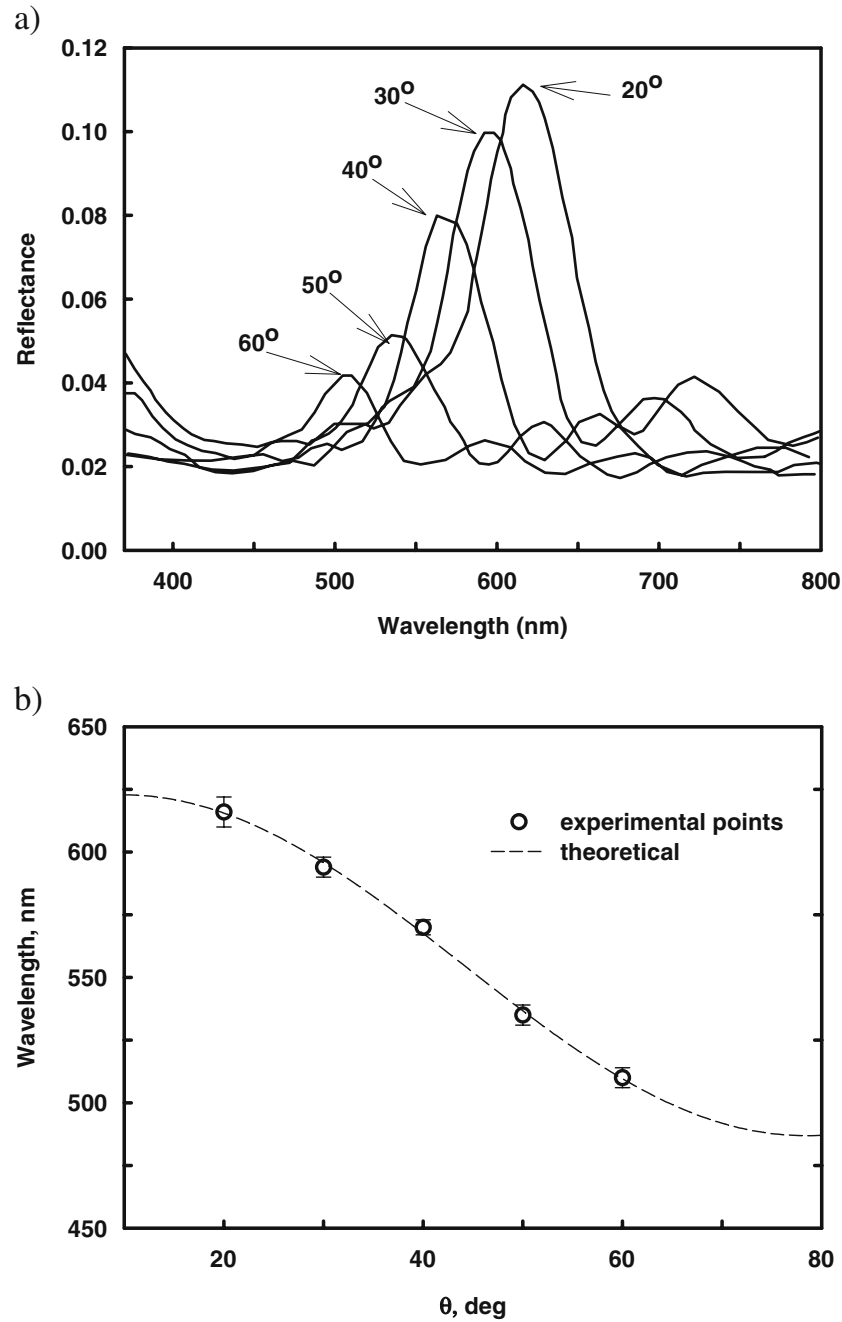

Fig. 3 a Optical reflectance spectra recorded at various incident angles for colloidal photonic crystals prepared from P(S/PGL2) microspheres $\left(D_{n}=271 \mathrm{~nm}\right.$ determined by SEM); b points indicate positions of the Bragg maxima as function of $\theta$ (angle between the incidence light and surface of reflecting plane). The dashed line in Fig. $3 \mathrm{~b}$ was obtained by finding values of $d_{111}$ and $n_{\text {eff }}$ providing the best fit of line calculated using Eq. 3 to experimental points. Values of these parameters are given in Table 2

$D_{n}=271 \mathrm{~nm}$. Figure $3 \mathrm{~b}$ shows also the plot of the wavelength of the peak maxima in the Bragg reflectance spectra as a function of $\theta$ for the colloidal crystal assemblies prepared from the same particles. It is worth noting that theoretical line described by Eq. 3 discussed below could be very well fitted to experimental points in the plot in Fig. $3 b$.

The positions of the diffraction peaks, $\lambda_{\max }$, for scattering of light from crystals are determined by the Bragg Eq. 2

$m \lambda_{\max }=2 n_{c} \cdot d_{h k l} \cdot \sin \theta_{B}$

where, $m$ is the order of diffraction, $\lambda_{\max }$ the Bragg peak wavelength, $n_{c}$ the refractive index of the crystal, $d_{\mathrm{hkl}}$ the 
Table 2 Comparison of optical parameters for $\mathrm{P}(\mathrm{S} / \mathrm{PGL})$ particles with $D_{n}=237$ and $D_{n}=271 \mathrm{~nm}$

\begin{tabular}{lll}
\hline$D_{n}$ of P(S/PGL) particles determined by SEM $(\mathrm{nm})$ & 237 & 271 \\
Bragg peak maximum value at $20^{\circ}(\mathrm{nm})$ & 558.5 & 616 \\
Interplanar spacings between 111 planes, $d_{111}(\mathrm{~nm})$ & 198.0 & 218.2 \\
$\begin{array}{l}\text { Diameter of P(S/PGL) particles }(D) \text { calculated from } \\
\quad \text { relation } d_{111}=(2 / 3)^{1 / 2} D(\mathrm{~nm})\end{array}$ & 243 & 267 \\
$\begin{array}{l}\text { Effective refractive index }\left(n_{\text {eff }}\right) \\
\text { Refractive index of particle }\left(n_{\text {particle }}=\varepsilon_{\text {particle }}{ }^{1 / 2}\right),\end{array}$ & 1.448 & 1.451 \\
$\quad$ calculated using Eq. 4 & & 1.57 \\
\hline
\end{tabular}

distance between diffracting planes, and $\theta_{\mathrm{B}}$ the Bragg angle (the angle between the incidence light and reflecting surface).

Equation 2 is often modified to Eq. 3 valid for $m=1$. Moreover, in Eq. 3, $n_{c}$ was replaced by $n_{\text {eff }}$ (for inhomogeneous arrays containing domains with different refractive indices) instead of $\theta_{B}$ the angle between the incidence light and the normal to the (111) planes $(\theta)$ has been used.

$\lambda_{\max }=2 d_{111}\left(n_{\mathrm{eff}}^{2}-\sin ^{2} \theta\right)^{1 / 2}$

The interplanar distance $d_{111}$, unit cell parameter $(a)$ and Miller indices $(h, k$, and $l)$ are related in the following way $d_{111}=a /\left(h^{2}+k^{2}+l^{2}\right)^{1 / 2}$. In the case of colloidal crystals with particle arrangement into $f c c$ cell $d_{111}=(2 / 3)^{1 / 2} D$, where $D$ is the sphere diameter.

Colloidal crystals from spherical polymer microspheres are composed of spherical particles and voids not filled with polymer material. The effective refractive index $n_{\text {eff }}$ of such materials can be approximated by formula (4)

$n_{\text {eff }}=\left(\varepsilon_{\text {particle }} \Phi+\varepsilon_{\text {air }}(1-\Phi)\right)^{1 / 2}$

where $\Phi$ is the filling fraction of the volume occupied by the particles (equal to 0.74 for the close-packed $f c c$ structure) and $\varepsilon_{\text {particle }}$ and $\varepsilon_{\text {air }}$ are dielectric constants equal to the square root of the refractive indices of particle material and air, respectively.

According to data in Table 2, it is evident that the number average diameter of particles determined from
SEM microphotographs is very close to particles diameters obtained from analysis of reflectance spectra of relevant colloidal crystals. It is also worth noting that the refractive indices for $\mathrm{P}(\mathrm{S} / \mathrm{PGL} 1)\left(D_{n}=237 \mathrm{~nm}\right)$ and $\mathrm{P}(\mathrm{S} / \mathrm{PGL} 2)\left(D_{n}=\right.$ $271 \mathrm{~nm})$ are essentially the same. Evidently, the small difference of composition of particles' interfacial layer (see data in Table 1) is insufficient to lead to significant differences of $n_{\text {particle. }}$.

One should notice also a great sensitivity of the Bragg peak position to diameters of microspheres. For example, for reflectance spectra recorded at $\theta=20^{\circ}$ the difference of particle diameters by $34 \mathrm{~nm}$ (from 237 to $271 \mathrm{~nm}$ ) manifests itself by moving the Bragg peak position by $57.5 \mathrm{~nm}$ (from 558.5 to $616 \mathrm{~nm}$ ).

Preparation and properties of colloidal crystals from P(S/PGL) microspheres with immobilized ovalbumin

$\mathrm{P}(\mathrm{S} / \mathrm{PGL})$ microspheres are known to be resistant to protein adsorption; however, upon activation of hydroxyl groups in particles' interfacial layer with 1,3,5-trichlorotriazine (TCT), they are able to bind proteins very effectively forming covalent linkages [28]. Thus, after initial activation with TCT ovalbumin was attached onto P(S/PGL) microspheres by incubation a sample of particles and ovalbumin in a PBS at $\mathrm{pH}$ 7.4. Incubation was carried on for $24 \mathrm{~h}$ at room temperature (for detailed protocol of ovalbumin immobilization see Experimental Part).

Surface concentrations of covalently immobilized ovalbumin, hydrodynamic diameters and electrophoretic mobilities of $\mathrm{P}(\mathrm{S} / \mathrm{PGL})$ microspheres without and with immobilized ovalbumin as well as Bragg peak positions in absorption spectra registered at $90^{\circ}$ for photonic crystals prepared from the abovementioned particles are given in Table 3.

It is worth noting that hydrodynamic diameter of $\mathrm{P}(\mathrm{S} / \mathrm{PGL})$ particles measured by PCS is larger than those measured in SEM microphotographs. Since SEM microphotographs were recorded for the dry particles and PCS measurements were carried on for particles suspended in water one could conclude
Table 3 Properties of uncoated and ovalbumin-coated $\mathrm{P}$ (S/PGL) microspheres particles in aqueous suspensions

\begin{tabular}{|c|c|c|c|c|}
\hline Microspheres & $\begin{array}{l}\text { Hydrodynamic } \\
\text { diameter }(\mathrm{nm}) \\
\text { determined } \\
\text { by PCS }\end{array}$ & $\begin{array}{l}\text { Surface } \\
\text { concentration } \\
\text { of ovalbumin, } \\
\left(\mathrm{g} / \mathrm{m}^{2}\right)\end{array}$ & $\begin{array}{l}\text { Molecules of } \\
\text { ovalbumin per } \\
\text { particle }\end{array}$ & $\begin{array}{l}\text { Electrophoretic } \\
\text { mobility in } \\
10^{-3} \mathrm{M} \mathrm{NaCl} \\
\left(\mathrm{m}^{2} / \mathrm{Vs}\right)\end{array}$ \\
\hline $\begin{array}{l}\mathrm{P}(\mathrm{S} / \mathrm{PGL} 1), \\
D_{n}=237 \mathrm{~nm} \\
\text { by SEM }\end{array}$ & 268 & 0 & & $-3.8 \times 10^{-8}$ \\
\hline P(S/PGL1)-OVA & 278 & $2.0 \times 10^{-4}$ & 490 & $-2.9 \times 10^{-8}$ \\
\hline $\begin{array}{l}\mathrm{P}(\mathrm{S} / \mathrm{PGL} 2), \\
D_{n}=271 \mathrm{~nm} \text { by } \\
\text { SEM }\end{array}$ & 301 & 0 & & $-4.1 \times 10^{-8}$ \\
\hline $\mathrm{P}(\mathrm{S} / \mathrm{PGL} 2)-\mathrm{OVA}, D_{n}$ & 345 & $1.93 \times 10^{-3}$ & 5,979 & $-3.5 \times 10^{-8}$ \\
\hline
\end{tabular}




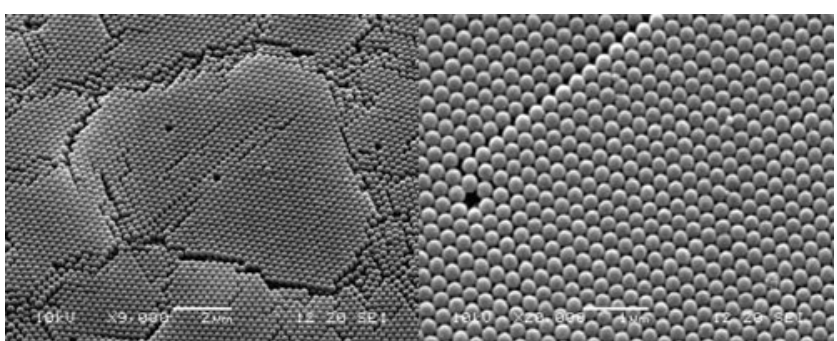

Fig. 4 SEM photographs of colloidal crystal from P(S/PGL2)-OVA microspheres

that polyglycidol rich interfacial layer of $\mathrm{P}(\mathrm{S} / \mathrm{PGL})$ microspheres is swollen in water what contributes of particles' hydrodynamic radii determined by the PCS method. Results suggesting swelling of shells of $\mathrm{P}(\mathrm{S} / \mathrm{PGL})$ particles were noticed also during our earlier studies [29].

Data in Table 3 indicate that binding of ovalbumin to $\mathrm{P}$ (S/PGL) microspheres leads to increasing particles' diameters. In the case of $\mathrm{P}(\mathrm{S} / \mathrm{PGL} 1)$ and $\mathrm{P}(\mathrm{S} / \mathrm{PGL} 2)$ microspheres the hydrodynamic diameters increase by 10 and $44 \mathrm{~nm}$ upon ovalbumin immobilization.

The bound ovalbumin with the particles surface effects in increase of their hydrodynamic diameters. The increased radius of $\mathrm{P}(\mathrm{S} / \mathrm{PGL})-\mathrm{OVA}$ microspheres complexes-of $5 \mathrm{~nm}$ for particles with $237 \mathrm{~nm}$ diameter and of $22 \mathrm{~nm}$ in the case of particles with $271 \mathrm{~nm}$ diameter-indicates different protein surface coverage density. Actually, the surface coverage with ovalbumin for $271 \mathrm{~nm}$ particles is ten times higher than for smaller ones (see Table 3). Since ovalbumin is a spherical 3D globular protein with molecular dimensions $7 \times 4.5 \times 5 \mathrm{~nm}^{3}$ [30] and that one molecule of this protein closely packed at the surface occupies $35-$ $40 \mathrm{~nm}^{2}$ at saturation at the air/water interface [9] one can calculate the fraction of covalently bound protein on particles in regard to the maximum coverage (at protein saturation on the surface). In the case of particles with

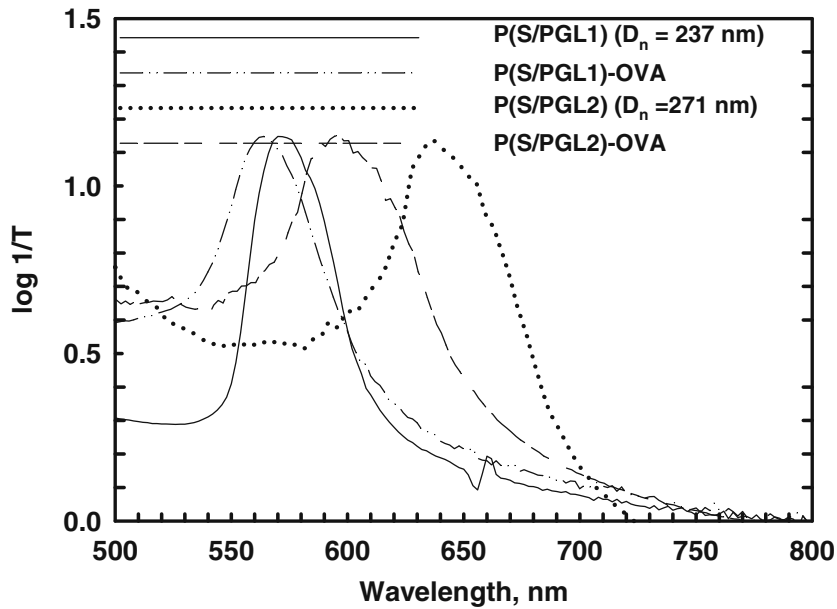

Fig. 5 Diffraction spectra of colloidal crystals formed from P(S/PGL1), $\mathrm{P}(\mathrm{S} / \mathrm{PGL} 2), \mathrm{P}(\mathrm{S} / \mathrm{PGL} 1)-\mathrm{OVA}$, and P(S/PGL2)-OVA microspheres
$237 \mathrm{~nm}$ diameter, the coverage fraction was $11 \%(490 / 4375$ protein molecules at saturation per particle) while for $271 \mathrm{~nm}$ particles the coverage exceeded $100 \%$ indicating a very dense packing at complete saturation of protein molecules at the surface or even partial penetration of swollen particles surface layer by this protein macromolecules (5979/5530/particle; see Table 3).

The modification of microspheres surface by ovalbumin was confirmed also by change of electrophoretic mobility of particles before and after protein immobilization. It was also found that ovalbumin, which is charged, modifies the charge of particles surface. The charge of bare particles derives from initiator-potassium persulfate-used for particles polymerization. The electrophoretic mobilities of particles with bound protein decreased, i.e., become less negative (data in Table 3).

Colloidal crystals of $\mathrm{P}(\mathrm{S} / \mathrm{PGL})-\mathrm{OVA}$ particles were prepared in the same way as in the case of particles without ovalbumin. Namely, $100 \mu l$ of particle suspension was placed onto glass slides pretreated as described in experimental section and left to dry at $25{ }^{\circ} \mathrm{C}$.

The $\mathrm{P}(\mathrm{S} / \mathrm{PGL})-\mathrm{OVA}$ microsphere arrays were imaged by SEM in order to check their organization (see Fig. 4), and characterized by diffraction spectra with purpose to determine changes in the Bragg peak positions induced by the immobilized ovalbumin. These spectra registered at $90^{\circ}$ for particle arrays $\mathrm{P}(\mathrm{S} / \mathrm{PGL} 1), \mathrm{P}(\mathrm{S} / \mathrm{PGL} 2), \mathrm{P}(\mathrm{S} / \mathrm{PGL1})-\mathrm{OVA}$, and $\mathrm{P}(\mathrm{S} / \mathrm{PGL} 2)-\mathrm{OVA}$ microspheres are shown in Fig. 5.

Diffraction spectra in Fig. 5 reveal that attachment of ovalbumin in shift of the Bragg peak to the lower wavelengths. The size of this shift depends on the surface fractions of covalently bound ovalbumin; a small $8 \mathrm{~nm}$ shift was observed for $0.105^{\circ}$ of the surface coverage with ovalbumin, whereas for the degree of surface coverage equal 0.967 this shift reached $42.5 \mathrm{~nm}$.

Usually, for arrays of particles with larger diameters, the position of Bragg peak is at the longer wavelength. However, while comparing the Bragg peak positions for $\mathrm{P}$ (S/PGL) and $\mathrm{P}(\mathrm{S} / \mathrm{PGL})-\mathrm{OVA}$ particles one should take into

Table 4 Properties of photonic crystals prepared from uncoated and ovalbumin-coated $\mathrm{P}(\mathrm{S} / \mathrm{PGL})$ particles

\begin{tabular}{|c|c|c|c|c|c|}
\hline $\begin{array}{l}\text { Type of } \\
\text { microspheres } \\
\text { in colloidal } \\
\text { crystal }\end{array}$ & $\begin{array}{l}\text { Wavelength of } \\
\text { the Bragg peak } \\
(\mathrm{nm}) \text {; spectra } \\
\text { registered at } \\
\theta=0^{\circ}\end{array}$ & $d_{111}, \mathrm{~nm}$ & $n_{\text {eff }}$ & $D, \mathrm{~nm}$ & $n_{\text {particle }}$ \\
\hline $\begin{array}{l}\mathrm{P}(\mathrm{S} / \mathrm{PGL} 2) \\
\left(D_{n}=271 \mathrm{~nm}\right. \\
\text { by SEM })\end{array}$ & 630.5 & 218.2 & 1.451 & 266.9 & 1.58 \\
\hline $\mathrm{P}(\mathrm{S} / \mathrm{PGL} 2)-\mathrm{OVA}$ & 597 & 233.4 & 1.406 & 286.1 & 1.52 \\
\hline
\end{tabular}


account not only differences in particle diameters but also differences in their refractive indices.

An angular dependence of the Bragg peak position for colloidal crystals from $\mathrm{P}(\mathrm{S} / \mathrm{PGL} 2)-\mathrm{OVA}$ microspheres analyzed in a similar manner as in the case of crystals from particles without ovalbumin (using Eqs. 3 and 4 allowed determination of $d_{111}$ interplanar spacing, $n_{\mathrm{eff}}$ refractive indices, particle diameters and particle refractive indices). These data are given in Table 4.

Data in Table 4 indicate that red shift due to an increase of particle diameters by $19.2 \mathrm{~nm}$ (from 266.9 to $286.1 \mathrm{~nm}$ ) more than compensated by blue shift due to a significant decrease of effective refractive index accompanying ovalbumin attachment.

\section{Conclusion}

Core-shell microspheres with polystyrene core and polyglycidol-enriched shells can be used for covalent immobilization of ovalbumin. Particles with and without attached albumin can be used for preparation of high quality colloidal crystals. Optical properties of these crystals (Bragg peak position) are strongly dependent on protein binding which influences particle diameter and refractive index. This work suggests that monitoring of optical properties of colloidal crystals made from particles suitable for protein attachment can be used as a principle for design of sensors for protein detection, in particular colloidal crystals from particles with immobilized antibodies could be considered as interesting candidates for design of sensors for detection of complementary antigens.

Acknowledgments This work was supported by the Polish and French Ministry of Science and Higher Education Research Project POLONIUM for 2008-2009.

Open Access This article is distributed under the terms of the Creative Commons Attribution Noncommercial License which permits any noncommercial use, distribution, and reproduction in any medium, provided the original author(s) and source are credited.

\section{References}

1. Wang A, Chen S-L, Dong P (2009) Mater Lett 63:1586-1589

2. Yamamichi J, Lida M, Ojima T, Handa Y, Yamada T, Kuroda R, Imamura T, Yano T (2009) Sens Actuators, B 143:349-356
3. Liu H, Zhang X, Gao Z (2010) Photonics Nanostruct Fundam Appl 8:131-139

4. Shu S, Yu D, Wang Y, Wang F, Wang Z, Zhong W (2010) J Cryst Growth 312:3111-3116

5. Gao Y, Elder SA (2000) Mater Lett 44:228-232

6. Dziomkina NV, Hempenius MA, Vancso GJ (2009) Colloids Surf A Physicochem Eng Asp 342:8-15

7. Gil SC, Seo YG, Kim S, Shin J, Lee W (2010) Thin Solid Films 518:5731-5736

8. Okamoto J, Kimura H, Tsuchida A, Okubo T, Ito K (2007) Colloids Surf B Biointerfaces 56:231-235

9. Basinska T, Slomkowski S, Dworak A, Panchev I, Chehimi MM (2001) Colloid Polym Sci 279:916-924

10. Pasche S, De Paul SM, Janos Vörös J, Spencer ND, Textor M (2003) Langmuir 19:9216-9225

11. George PA, Donose BC, Cooper-White JJ (2009) Biomaterials $30: 2449-2456$

12. Hamilton-Brown P, Gengenbach T, Griesser HJ, Meagher L (2009) Langmuir 25:9149-9156

13. Wang H, Ren J, Hlaing A, Yan M (2011) J Colloid Interface Sci 354:160-167

14. Zhang J, Bai Yang (2010) Adv Funct Mater 20:3411-3424

15. Jiang P, Bertone JF, Hwang KS, Colvin VL (1999) Chem Mater $11: 2132-2140$

16. Jethmalani JM, Sunkara HB, Ford WT, Willoughby SL, Ackerson BJ (1997) Langmuir 13:2633-2639

17. Vos WL, Sprik R, van Blaaderen A, Imhof A, Lagendijk A, Wegdam GH (1996) Phys Rev B 53:16231-16235

18. Massé P, Reculusa S, Clays K, Ravaine S (2006) Chem Phys Lett 422:251-255

19. Massé P, Vallée AL, Dechézelles JF, Rosselgong J, Cloutet E, Cramail H, Zhao XS, Ravaine S (2009) J Phys Chem C 113:14487-14492

20. Szamocki R, Massé P, Ravaine S, Ravaine V, Hempelmann R, Kuhn A (2009) J Mater Chem 19:409-414

21. Bardosova M, Pemble ME, Povey IM, Tredgold RH, Whitehead DE (2006) Appl Phys Lett 89:093116-093118

22. Debord JD, Eustis S, Debord SB, Lofye MT, Lyon LA (2002) Adv Mater 14:658-662

23. Ge J, Hu Y, Yin Y (2007) Angew Chem Int Ed 46:74287431

24. Xu X, Friedman G, Humfeld KD, Majetich SA, Asher SA (2002) Chem Mater 14:1249-1256

25. Dworak A, Panchev I, Trzebicka B, Walach W (1998) Polym Bull 40:461-468

26. Briggs D (1990) In: Briggs D, Seah MP (eds) Practical surface analysis, vol 1, Auger and X-ray photoelectron spectroscopy, 2nd edn. Wiley, New York, pp 437-483

27. Lowry OH, Rosenbrough NJ, Farr AL, Randall RJ (1951) J Biochem 193:265-275

28. Basinska T, Wisniewska M, Chmiela M (2005) Macromol Biosci 5:70-77

29. Basinska T, Slomkowski S, Kazmierski S, Chehimi MM (2008) Langmuir 24:8465-8472

30. Stein PE, Leslie AGW, Finch JT, Carrell RW (1991) J Mol Biol 221:941-959 